\title{
Erratum to: Poster Abstracts, 17th Annual Meeting of the International Association of Medical Science Educators, St. Andrews, Scotland, UK, June 8-11, 2013
}

Erratum to: The Journal of the International Association of Medical Science Educators, Med Sci Educ 2013; 23(4S): 668-725

DOI 10.1007/BF03341701

Abstract 218-Team-Based and Interprofessional Education: The Learning of Anatomy by Medical Students from Different Backgrounds in a Graduate Entry Course was published without authorship. Authors should have been:

Michelle Machado ${ }^{1}$ and Norman Eizenberg ${ }^{1,2}$

${ }^{1}$ Gippsland Medical School, Monash University

${ }^{2}$ Department of Anatomy and Developmental Biology,

Monash University, Clayton

michelle.machado@monash.edu 